\title{
Alternative Methods of Preparation of Soluble Keratin from Chicken Feathers
}

\author{
Izabela Sinkiewicz $^{1} \cdot$ Agata Śliwińska $^{1} \cdot$ Hanna Staroszczyk ${ }^{1} \cdot$ Ilona Kołodziejska $^{1}$
}

Received: 25 January 2016/Accepted: 25 August 2016/Published online: 31 August 2016

(C) The Author(s) 2016. This article is published with open access at Springerlink.com

\begin{abstract}
Huge amount of keratinous waste, especially birds' feathers, demands more value-added application instead of dumping. The present work reports the results of experiments aimed at preparing soluble keratin useful for novel bioproduct formation. The effect of thermo-chemical treatments with various reducing agents, i.e. 2-mercaptoethanol, dithiothreitol, sodium $m$-bisulphite, and sodium bisulphite, as well as sodium hydroxide, on the yield of keratin extracted from chicken feathers was determined. It was shown that after 2-h reduction with 2-mercaptoethanol and sodium bisulphite, the yield of soluble keratin was about equal and amounted to 84 and $82 \%$, respectively. The cheaper and harmless sodium bisulphite additionally decreased the extraction time to $1 \mathrm{~h}$ with the same yield. Moreover, treatment of the feathers with $2.5 \% \mathrm{NaOH}$ further improved the extraction effectiveness by increasing the yield up to $94 \%$. The results of the study demonstrate the viability of hydrolytic processes to obtain soluble keratin useful for biodegradable film formation for food application, that are harmless and more effective than solubilization by reduction of the disulphide bonds.
\end{abstract}

Hanna Staroszczyk

hanna.staroszczyk@pg.gda.pl

1 Department of Food Chemistry, Technology and Biotechnology, Gdansk University of Technology, G. Narutowicza 11/12, 80-233 Gdańsk, Poland

\section{Graphical Abstract}



Keywords Feather waste $\cdot$ Keratin hydrolysis $\cdot$ Keratin reduction $\cdot$ Soluble keratin yield

\section{Introduction}

Keratin is the most abundant structural fibrous protein of hair, skins, bristles, horns, hooves, and bird feathers. Millions tonnes of keratinous wastes are generated annually globally, especially in wool textile industry and in poultry slaughterhouses [1]. The bird feathers consist of approximately $90 \%$ keratin. The worldwide annual feather offal amounts to about $8 \times 10^{5}$ tonnes [2]. Usually it is deposited in landfills. Due to a large variety of microflora present on the feathers, including pathogens, they should be treated quickly. Although, the main method for disposal of feather waste is incineration, high energy consumption and emissions of large amount of carbon dioxide makes it not preferable [3]. Another way is composting them with manure, but the composting process is long-lasting and is subjected to special requirements of the veterinary inspection concerning a closed composting area with a sewage carry systems, and periodic microbiological tests [4]. A serious problem regarding composting is also 
odorous emission of hydrogen sulfide that persists long in the air. Despite Tronina and Bubel [5] stated that composting may not fully inactivate pathogenic microorganisms, properly conducted composting, according to regulations, must involve thermal phase of specific parameters, that allows for sufficient sanitation of the composted biomass. An alternative method of feather waste utilization is processing to soluble keratin that could become useful for novel bioproducts formation.

Despite many years of research devoted to converting raw keratin-based materials into soluble forms of keratin, there are still problems due to high resistance of keratin to various chemical reagents and enzymes. The highly crosslinked network structure with numerous disulfide and hydrogen bonds, as well as hydrophobic interactions, and tightly packed keratin microfibrils causes that the protein is insoluble in water, solutions of weak alkali and acids, and most organic solvents. Soluble keratin can be received by alkaline, acid, or enzymatic hydrolysis, reduction or oxidation of the disulphide bonds, thermal treatment in some organic solvents and various hydrothermal methods [6-8].

Chemical hydrolysis leads to destruction of the native structure of keratin and the feather waste becomes more water-soluble. Acidic hydrolysis is highly efficient, but causes loss of some amino acids, e.g. tryptophan [9]. Alkaline hydrolysis is slower and can be incomplete, but the loss of amino acids is lower. The yield of the hydrolytic processes depends on $\mathrm{pH}$, temperature and reaction time, and also on the type and concentration of acid or base used. The solubility and stability of the hydrolysates depend on the degree of protein degradation [10]. Chemical hydrolysis is often assisted by heating to ensure high yield; however, high temperature can increase the destruction of amino acids.

The enzymatic process for obtaining soluble keratin requires either pure keratinases isolated from microorganisms or the microorganisms themselves. The keratinases capable of keratin degradation are extracellular serine proteases or metallo-proteases. Mesophilic fungi and actinomycetes [11], and also some species of Bacillus [12] produce these enzymes as the response to the presence of keratin. Enzymatic hydrolysis runs under mild conditions during which low energy is used, but it must be assisted by chemical reducing agents degrading keratin's disulphide bonds [13]. Furthermore, the enzyme activity and yield of soluble keratin are too low to make the enzymatic process suitable for industrial applications. Reports on application of thermo-chemical treatment of keratins have recently appeared, however in different experimental layout, aimed in aiding subsequent enzymatic digestion [14].

Reduction and oxidation of the disulphide bonds render soluble keratin forms containing undegraded amino acids.
Reduction of keratin by 2-mercaptoethanol, dithiothreitol (DTT) or dithioerythritol, thioglycolic acid, glutathione, sulphites, and bisulphite generates free cysteine residues, and the resulting cysteine-containing derivatives are called "kerateines" [7, 15-18]. They are less polar and more stable in acidic and alkaline solutions than the oxidized derivatives, and they contain amino acid residues capable of re-crosslinking. The reduction of keratin is a multi-step, long lasting process in which sulphitolysis is a key reaction. The disulphide bonds are disrupted by sulphite to give cysteine thiol (reduced keratin) and cysteineS-sulphonate residue (Bunte salt):

$$
\begin{aligned}
& \text { Keratin }-\mathrm{Cys}-\mathrm{S}-\mathrm{S}-\mathrm{Cys}-\text { Keratin }+\mathrm{SO}_{3}^{2-} \\
& \quad \rightarrow \text { Keratin }-\mathrm{Cys}-\mathrm{S}^{-}+\text {Keratin }-\mathrm{Cys}-\mathrm{SSO}_{3}^{-}
\end{aligned}
$$

where Keratin-Cys- $\mathrm{S}^{-}$is the reduced keratin and KeratinCys- $\mathrm{SSO}_{3}{ }^{-}$is the Bunte salt [19]. As the majority of the keratin remains trapped within the protective structures, during this reaction a denaturing solvent, such as urea, thiourea, transition metal hydroxides, surfactant solutions, and combination thereof should be applied, to limit the effects of ionic and hydrogen bonds interaction [16, 20]. In turn, addition of sodium dodecylsulfate (SDS) provides faster and more efficient extraction by formation of complexes keratin-SDS, and prevents protein aggregation [15]. The reduction process is industrially usable. 2-Mercaptoethanol gives high yield and does not damage the keratin. Unfortunately, it is harmful, and its high cost makes it industrially not viable. Other thiol compounds provide lower extraction yield that is not sufficient for industrial application.

During keratin oxidation by using hydrogen peroxide, potassium permanganate, and organic peracids, the disulphide bonds are converted into sulfonic acid groups. As a result, cysteic acid derivatives are formed, which are referred as "keratoses". After oxidation the regeneration of the disulphide bonds during reconstitution of keratin structures is impossible [21-23].

Another method of solubilisation of feathers is thermal treatment in dimethyl sulfoxide, compound with low toxicity. This technique of soluble keratin preparation was widely used by numerous researchers, however on laboratory scale, for obtaining a substrate for determination of keratinolytic activity [8].

To obtain soluble keratin also hydrothermal treatment can be applied at 100 to $150{ }^{\circ} \mathrm{C}$ and $1.5 \times 10^{5} \mathrm{~Pa}$. These conditions lead to changes in the protein structure and degradation of amino acids. Another disadvantage of this method is high cost as a result of high energy requirement [2]. Thus, cheaper techniques preventing unwanted changes of amino acids are needed.

Extraction of keratin from feather waste and the use of soluble keratin to develop novel, useful bioproducts would 
be very valuable for decreasing the environmental problems. Keratin-based materials are suitable for biomedical [18, 23, 24], cosmetical [25] and agricultural applications [26]. Due to biodegradability and high mechanical strength, keratin materials have a promising potential for biodegradable packaging production [27, 28].

Biodegradable packaging materials may provide an alternative to undegradable synthetics, so far the most often used for this purpose, which cause environmental pollution. Degradation of natural polymeric materials leads to formation of water, carbon dioxide, and non-toxic inorganic substances. These materials are good barriers against oxygen and carbon dioxide, and prevent oxidation of food and migration of volatile substances [29].

The objective of this work was to obtain soluble keratin from chicken feathers to use them for biodegradable film formation for food application. The usefulness of various reducing substances, such as 2-mercaptoethanol, DTT, sodium $m$-bisulphite and sodium bisulphite, as well as sodium hydroxide, to turn chicken feathers into soluble forms, was investigated in respect to process yield. Song et al. [27, 28] found that packaging films could be obtained from keratin hydrolysates, but they did not show the yield of the soluble keratin. To our best knowledge, this is the first report showing not only how to prepare keratin hydrolysates from feathers for formation of biodegradable packaging materials, but also the yield of the products obtained in reduction and hydrolytic processes.

\section{Materials and Methods}

\section{Materials}

White chicken feathers were supplied by a local company ("Drobful", Kczew, Poland). 2-Mercaptoethanol and urea (Sigma, USA), DTT (Fluka, USA), SDS (Merck), sodium $m$-bisulphite, sodium bisulphite (40\% solution), and $\mathrm{NaOH}$ (POCH, Poland) were used for keratin extraction.

\section{Pretreatment of the Feathers}

Wet feathers were washed with water at $60{ }^{\circ} \mathrm{C}$, dried at $50{ }^{\circ} \mathrm{C}$ for $24 \mathrm{~h}$, and cut into small filaments with a length of $0.75 \mathrm{~mm}$ using ultra centrifugal mill (Retsch, Type ZM 200). This material was treated in a Soxhlet apparatus for $12 \mathrm{~h}$ with petroleum ether to remove fatty material, followed by evaporation of the residual solvent. The dry defatted feathers were stored at room temperature in closed containers, and used for determination of dry weight and total protein.

\section{Dry Weight and Total Protein}

The dry weight of defatted feathers was measured according to AOAC [30], and total nitrogen was determined by Kjeldahl method [30]. The established conversion factor of nitrogen to protein was 5.71 [2].

\section{Extraction of Feather Keratin}

In the reduction process defatted feathers $(1 \mathrm{~g})$ were put in $25 \mathrm{~mL}$ of aqueous solutions containing either 2-mercaptoethanol, sodium $m$-bisulphite, sodium bisulfite or DTT, and the mixture was shaken at $50{ }^{\circ} \mathrm{C}$ for $2 \mathrm{~h}$. The components used in this reaction mixtures are shown in Table 1. In the hydrolytic process the defatted feathers $(10 \mathrm{~g})$ were mixed with $100 \mathrm{~mL}$ of sodium hydroxide solutions of various concentrations 1.0, 1.5, 2.0 or $2.5 \mathrm{wt} \%$ at $70{ }^{\circ} \mathrm{C}$ for 75 min with a magnetic stir bar to prevent aggregation of the feathers during the reaction. After both processes, the resulting mixture was centrifuged at $9000 \times g$ for $15 \mathrm{~min}$ to separate the insoluble material, and the supernatant was filtered through a folded filter. The filtrate obtained with various reducing agents was dialysed in distilled water using Spectra/Por dialysis membranes of regenerated cellulose (MWCO 3500-5000 Da) for $72 \mathrm{~h}$ changing the outer water every day. The keratin sediment was washed several times with distilled water, and centrifuged at $9000 \times g$ for $15 \mathrm{~min}$. The insoluble residue was dried at $105^{\circ} \mathrm{C}$ until a constant weight was obtained. The yield of soluble keratin was determined by measuring the dry weight of insoluble material and calculated from:

Table 1 Keratin reduction methods at $50{ }^{\circ} \mathrm{C}$ adopted by different authors

\begin{tabular}{|c|c|c|}
\hline $\begin{array}{l}\text { Number } \\
\text { of method }\end{array}$ & Extraction solutions & Reference \\
\hline 1 & $\begin{array}{l}\text { 1.66 M 2-mercaptoethanol } \\
8 \mathrm{M} \text { urea } \\
0.26 \mathrm{M} \text { SDS } \\
0.2 \mathrm{M} \text { Tris- } \mathrm{HCl}\end{array}$ & [29] \\
\hline 2 & $\begin{array}{l}0.5 \mathrm{M} \text { sodium bisulphite }{ }^{1} \\
8 \mathrm{M} \text { urea } \\
0.08 \mathrm{M} \text { SDS }\end{array}$ & [17] \\
\hline 3 & $\begin{array}{l}0.5 \mathrm{M} \text { sodium } m \text {-bisulphite }{ }^{1} \\
8 \mathrm{M} \text { urea } \\
0.2 \mathrm{M} \mathrm{SDS}\end{array}$ & [18] \\
\hline 4 & $\begin{array}{l}0.1 \mathrm{M} \mathrm{DTT}^{1} \\
8 \mathrm{M} \text { urea } \\
0.1 \mathrm{M} \text { Tris-HCl }\end{array}$ & [18] \\
\hline
\end{tabular}

\footnotetext{
1 Reducing substance
} 
$\mathrm{Y}(\%)=\left[\left(\mathrm{m}_{\mathrm{o}}-\mathrm{m}_{\mathrm{dry}}\right) / 0.903 \times \mathrm{m}_{\mathrm{o}}\right] \times 100 ;$

where $\mathrm{m}_{\mathrm{o}}$-initial wet weight of feathers $[\mathrm{g}], \mathrm{m}_{\mathrm{dry}}$ - dry weight of insoluble residue [g], 0.903 - dry weight content of defatted feathers as decimal fraction.

\section{Statistical Analysis}

The results presented in the tables are average values from at least three replications. The data were evaluated by analysis of variance (one-way procedure) using the program SigmaPlot 11.0 (Systat Software, Germany) and the differences between the means determined by Tukey multiple test $(p<0.05)$.

\section{Results and Discussion}

Protein content in the chicken feathers used in this study amounted to $88 \%$. The effect of reducing agents used on the yield of soluble keratin is shown in Table 2. The highest yield was obtained by treatment with 2-mercaptoethanol and sodium bisulphite. Although the yield was also high when DTT was used, the solution obtained by this method became partially insoluble after dialysis, so this reducing agent was not suitable.

Schrooyen et al. [16] reported the yield of keratin extracted from feathers by 2-mercaptoethanol to be approximately $75 \%$. Poole et al. [32] showed that sodium sulphite gave a yield of $62 \%$. The lower yield reported by the former authors than that shown in Table 2, 75 and $84 \%$, respectively, could be the result of different conditions during extraction, such as a shorter reaction time of $30 \mathrm{~min}$ at lower temperature of $40{ }^{\circ} \mathrm{C}$. Apart from extraction of keratin from chicken feather a wide number of procedures with reducing agents are also used for dissolving keratin from wool. Keratin extracted from wool by 2-mercaptoethanol gave a yield of ca. $50 \%$ [33], sodium bisulphite and $m$-sodium bisulphite ca. $30 \%$ [17, 18], and DTT ca. $80 \%$ [18]. Thompson and O`Donnell [34]

Table 2 Effect of various reducing substances on the yield of keratin extracted for $2 \mathrm{~h}$ from chicken feathers

\begin{tabular}{ll}
\hline Reducing substance & Keratin yield $[\%]^{1}$ \\
\hline 2-mercaptoethanol & $83.8 \pm 0.25^{\mathrm{a}}$ \\
Sodium bisulphite & $82.4 \pm 0.12^{\mathrm{b}}$ \\
Sodium $m$-bisulphite & $62.9 \pm 1.00^{\mathrm{d}}$ \\
DTT & $77.6 \pm 1.40^{\mathrm{c}}$
\end{tabular}

1 Results are expressed as means of four measurements \pm standard deviation. The values in a column marked with various letters differ significantly $(p<0.05)$

solubilized wool keratin with thioglycolic acid to a maximum value of $70 \%$.

Instead of the toxic 2-mercaptoethanol, it is preferable to use sodium bisulphite. It is as effective as 2-mercaptoethanol, cheaper, and harmless, so in the next step the effect of the time of treatment with sodium bisulphite on the yield was studied. It can be seen in Table 3 that in the time range $1-5 \mathrm{~h}$ the highest yield, $82 \%$, was obtained in just 1-h extraction with sodium bisulphite.

An alternative method may be the preparation of soluble keratin by enzymatic hydrolysis under mild conditions. However, the yield of such reaction is not high enough, because of high cross-linking of keratin and tightly compressed structure of its microfibrils which make it not susceptible to the currently available proteolytic enzymes. A better method could be alkaline hydrolysis, so far widely used in the production of keratin fodder meal [35]. Song et al. [27, 28] found that keratin hydrolysate could find particular application for biodegradable film formation. Since, the authors did not show if it was an industrially viable method, therefore, we decided to check the yield of keratin extraction using various concentrations of aqueous $\mathrm{NaOH}$ solutions (Table 4).

As can be seen in Table 4, a gradual increase of the yield with the increase of concentration of $\mathrm{NaOH}$ solution from 1.0 to $2.5 \%$ was observed. Treatment with $1.5 \%$ $\mathrm{NaOH}$ increased the yield three times in comparison with a

Table 3 Effect of time of treatment with sodium bisulphite on the yield of keratin from chicken feathers

\begin{tabular}{ll}
\hline Concentration of $\mathrm{NaOH}$ solution $(\%)$ & Keratin yield $(\%)^{1}$ \\
\hline 1.0 & $29.3 \pm 0.16^{\mathrm{a}}$ \\
1.5 & $80.1 \pm 0.94^{\mathrm{b}}$ \\
2.0 & $90.8 \pm 0.64^{\mathrm{c}}$ \\
2.5 & $93.7 \pm 0.49^{\mathrm{d}}$ \\
\hline
\end{tabular}

1 Results are expressed as means of four measurements \pm standard deviation. The values in a column marked with various letters differ significantly $(p<0.05)$ 
value obtained for $1.0 \%$ alkali, and 2 and $2.5 \% \mathrm{NaOH}$ gave the yield higher than that obtained by using of reducing agents during $2 \mathrm{~h}$ extraction (Table 2). Moreover, this yield was even higher than that obtained with sodium bisulphite used just after $1 \mathrm{~h}$ (Table 3 ).

\section{Conclusions}

Among the selected reducing agents used in 2-h extraction of feather keratin 2-merkaptoethanol and sodium bisulphite appear to be the most effective with maximum yield. The cheaper and harmless sodium bisulphite gives high yield just after 1-h reaction. However, treatment of the feathers with $2.5 \% \mathrm{NaOH}$ increases the yield even by $10 \%$. The replacement of reduction reactions in keratin extraction by alkaline hydrolysis makes it more industrially viable and eliminates corrosive substances used which are a threat to the environment.

Open Access This article is distributed under the terms of the Creative Commons Attribution 4.0 International License (http://crea tivecommons.org/licenses/by/4.0/), which permits unrestricted use, distribution, and reproduction in any medium, provided you give appropriate credit to the original author(s) and the source, provide a link to the Creative Commons license, and indicate if changes were made.

\section{References}

1. Aluigi, A., Zoccola, M., Vineis, C., Tonin, C., Ferrero, F., Canetti, M.: Study on the structure and properties of wool keratin regenerated from formic acid. Int. J. Biol. Macromol. 41, 266-273 (2007)

2. Grazziotin, A., Pimentel, F.A., De Jong, E.V., Brandelli, A.: Nutritional improvement of feather protein by treatment with microbial keratinase. Anim. Feed Sci. Technol. 1261, 135-144 (2006)

3. Suzuki, Y., Tsujimoto, Y., Matsui, H., Watanabe, K.: Decomposition of extremely hard-to-degrade animal proteins by thermophilic bacteria. J. Biosci. Bioeng. 102, 73-81 (2006)

4. Commission Regulation (EU) No 142/2011 implementing Regulation (EC) No. 1069/2009 of the European Parliament and of the Council laying down health rules as regards animal byproducts and derived products not intended for human consumption and implementing Council Directive 97/78/EC as regards certain samples and items exempt from veterinary checks at the border under that Directive. http://eur-lex.europa. eu/legal-content/EN/TXT/PDF/?uri=CELEX:32011R0142\&from= EN. Accessed January 2016 (2011)

5. Tronina, P., Bubel, F.: Production of organic fertilizer from poultry feather wastes excluding the composting process. Pol. J. Chem. Technol. 10, 33-36 (2008)

6. Chojnacka, K., Górecka, H., Michalak, I., Górecki, H.: A review: valorization of keratinous materials. Waste Biomass Valor. 2, 317-321 (2011)

7. Hill, P., Brantley, H., Van Dyke, M.: Some properties of keratin biomaterials: kerateines. Biomaterials 31, 585-593 (2010)
8. Wawrzkiewicz, K., Łobarzewski, J., Wolski, T.: Intracellular keratinase of Trichophyton gallinae. J. Med. Vet. Mycol. 25, 261-268 (1987)

9. Zhang, J., Li, Y., Li, J., Zhao, Z., Liu, X., Li, Z., Han, Y., Hu, J., Chen, A.: Isolation and characterization of biofunctional keratin particles extracted from wool wastes. Powder Technol. 246, 356-362 (2013)

10. Coward-Kelly, G., Agbogbo, F.K., Holtzapple, M.T.: Lime treatment of keratinous materials for the generation of highly digestible animal feed: 2. Animal hair. Bioresour. Technol. 97, 1344-1352 (2006)

11. Kunert, J.: Keratin decomposition by dermatophytes II. Presence of s-sulfocysteine and cysteic acid in soluble decomposition products. Z. Allgemeine Mikrobiol. 16, 97-105 (1976)

12. Kim, J.M., Lim, W.J., Suh, H.J.: Feather-degrading Bacillus species from poultry waste. Process Biochem. 37, 287-291 (2001)

13. Kumar, C.G., Takagi, H.: Microbial alkaline proteases: from a bioindustrial viewpoint. Biotechnol. Adv. 17, 561-594 (1999)

14. Łaba, W., Kopeć, W., Chorążyk, D., Kancelista, A., Piegza, M., Malik, K.: Biodegradation of pretreated pig bristles by Bacillus cereus B5esz. Int. Biodeter. Biodegr. 100, 116-123 (2015)

15. Schrooyen, P.M.M., Dijkstra, P.J., Oberthür, R.C., Bantjes, A., Feijen, A.: Stabilization of solutions of feather keratins by sodium dodecyl sulfate. J. Colloid Interface Sci. 240, 30-39 (2001)

16. Schrooyen, P.M.M., Dijkstra, P.J., Oberthür, R.C., Bantjes, A., Feijen, J.: Partially carboxymethylated feather keratins. 1. Properties in aqueous systems. J. Agric. Food Chem. 48, 4326-4334 (2000)

17. Tonin, C., Aluigi, A., Vineis, C., Varesano, A., Montarsolo, A., Ferrero, F.: Thermal and structural characterization of poly(ethylene-oxide)/keratin blend films. J. Therm. Anal. Calorim. 89, 601-608 (2007)

18. Vasconcelos, A., Freddi, G., Cavaco-Paulo, A.: Biodegradable materials based on silk fibroin and keratin. Biomacromolecules $\mathbf{9}$, 1299-1305 (2008)

19. Maclaren, J.A., Milligan, B.: Wool Science: The Chemical Reactivity of the Wool Fiber. Science Press, Marrickville (1981)

20. Nakamura, A., Arimoto, M., Takeuchi, K., Fujii, T.: A rapid extraction procedure of human hair proteins and identification of phosphorylated species. Biol. Pharm. Bull. 25, 569-572 (2002)

21. Breinl, F., Baudisch, O.: The oxidative breaking up of keratin through treatment with hydrogen peroxide. Z. Physiol. Chem. 52, 158-169 (1907)

22. Lissizin, T.: Behavior of keratin sulfur and cystine sulfur in the oxidation of these proteins by potassium permanganate. Biochem. Bull. 4, 18-23 (1915)

23. Sierpinski, P., Garrett, J., Ma, J., Apel, P., Klorig, D., Smith, T., Koman, L.A., Atala, A., Van Dyke, M.: The use of keratin biomaterials derived from human hair for the promotion of rapid regeneration of peripheral nerves. Biomaterials 29, 118-128 (2008)

24. Tanabe, T., Okitsu, N., Tachibana, A., Yamauchi, K.: Preparation and characterization of keratin-chitosan composite films. Biomaterials 23, 817-825 (2002)

25. European Patent No. 1731528 A1. Process for producing solubilized keratin. https://data.epo.org/gpi/EP1731528A1-PRO CESS-FOR-PRODUCING-SOLUBILIZED-KERATIN. Accessed January 2016 (2006)

26. Vesela, M., Friedrich, J.: Amino acid and soluble protein cocktail from waste keratin hydrolysed by a fungal keratinase of Paecilomyces marquandii. Biotechnol. Bioprocess Eng. 14, 84-90 (2009)

27. Song, N.B., Lee, J.H., Al Mijan, M., Song, K.B.: Development of a chicken feather protein film containing clove oil and its 
application in smoked salmon packaging. LWT-Food Sci. Technol. 57, 453-460 (2014)

28. Song, N.B., Jo, W.S., Song, H.Y., Chung, K.S., Won, M., Song, K.B.: Effects of plasticizers and nano-clay content on the physical properties of chicken feather protein composite films. Food Hydrocoll. 31, 340-345 (2013)

29. Siracusa, V., Rocculi, P., Romani, S., Rosa, M.D.: Biodegradable polymers for food packaging: a review. Trends Food Sci. Technol. 19, 634-643 (2008)

30. AOAC. In Helrich, K. (ed.) Official methods of analysis (15th ed.). Virginia: Association of Official Analytical Chemists (1990)

31. Martelli, S.M., Moore, G., Paes, S.S., Gandolfo, C., Laurindo, J.B.: Influence of plasticizers on the water sorption isotherms and water vapor permeability of chicken feather keratin films. LWTFood Sci. Technol. 39, 292-301 (2006)
32. Poole, A.J., Lyons, R.E., Church, J.S.: Dissolving feather keratin using sodium sulphide for bio-polymer applications. J. Polym. Environ. 19, 995-1004 (2011)

33. Yamauchi, K., Yamauchi, A., Kusunoki, T., Kohda, A., Konishi, Y.: Preparation of stable aqueous solution of keratins, and physiochemical and biodegradational properties of films. J. Biomed. Mater. Res. 31, 439-444 (1996)

34. Thompson, E.O.P., O`Donnell, I.J.: Oxidized wool. I. Comparison of the completeness of oxidation with peracetic and performic acids. Aust. J. Biol. Sci. 12, 282-293 (1959)

35. Mokrejs, P., Svoboda, P., Hrncirik, J., Janacova, D., Vasek, V.: Processing poultry feathers into keratin hydrolysate through alkaline-enzymatic hydrolysis. Waste Manage. Res. 29, 260-267 (2011) 